Original Article

\title{
CORRELATION BETWEEN BMI AND PREGNANCY OUTCOME AM ONG POSTNATAL MOTHERS WITH PREGNANCY INDUCED HYPERTENSION IN SELECTED HOSPITALS BANGALORE
}

\author{
Prathima $\mathrm{P}^{1} \& \mathrm{~S}$ Anuchitra \\ ${ }^{1} \mathrm{HOD}$, Department of OBG, Universal College of Nursing, IIM B post Arekere Micolayout Bannerghatta Main Road, \\ Bangalore, ${ }^{2}$ Vice \& Principal, HOD, Department of OBG, P.D. Bharatesh College of Nursing, Belgaum. \\ Correspondence : \\ Prathima P \\ HOD, Department of OBG, Universal College of Nursing, IIM B post Arekere Micolayout , Bannerghatta M ain road, Bangalore - 76 \\ M obile : +9199867 78622 E-mail : prathima_1978@ymail.com
}

\section{Abstract:}

Title : Correlation between BM I and pregnancy Outcome among postnatal mothers with pregnancy Induced hypertension in selected hospital Bangalore.

Objectives: To identify and correlate BM I and pregnancy Outcome among postnatal mothers with pregnancy Induced hypertension.

Method : A non experimental correlation design was utilized among 80 postnatal mothers who were diagnosed as Pregnancy induced hypertension during their antenatal period selected as samples by using purposive sampling technique. Demographic data were collected by interview method, their BMI was calculated, pregnancy outcomes were identified from records by using an outcome checklist.

Results: Underweight mothers had low birth weight babies and received NICU care. Among normal weight mothers $17.5 \%$ delivered by LSCS, $15 \%$ babies were low birth weight babies 12.5 were preterm babies among them $10 \%$ received NICU care. In the overweight group $18.75 \%$ undergone LSCS, $18.75 \%$ were LBW and $1.25 \%$ VLBW, $8.75 \%$ babies were preterm, $12.5 \%$ newborn received NICU care. Among Obese mothers $8.75 \%$ delivered by LSCS, $6.25 \%$ of $L B W$ babies, $5 \%$ were preterm and all of them received NICU care. There is a positive correlation between BMI and diagnosis and type of delivery. Significant at .01 and .05 Level ( $p$ value .008 and .019 respectively). Negative correlation between birth weight and diagnosis and gestational age. $r=-.499$ significant at .01 level ( $p$ value .000$)$

Conclusion : Obesity and under weight is a leading, preventable cause of mortality worldwide. Preeclampsia increases maternal and perinatal morbidity and mortality rates. All women who are in reproductive age group and under risk to develop pregnancy induced hypertension need to be educated about to maintenance of normal weight before pregnancy. Nurses have more responsibility on creating awareness among women how to maintain normal weight to avoid development of complications to the mother and new born.

Keywords: BM I, Pregnancy outcome, Pregnancy Induced Hypertension, Low birth weight.

\section{Introduction :}

Uncomplicated course of pregnancy, which results in normal growth and development of the foetus, is dependent on many factors, individual one as well as factors associated with one another. In addition to

\begin{tabular}{|c|}
\hline Access this article online \\
\hline Quick Response Code \\
\hline
\end{tabular}

influence of environment and genetic predisposition one of the factors is maternal weight before and during gestation.

Ninety nine \% of maternal deaths occur in developing countries. In developing countries a quarter of a million women still die in pregnancy and childbirth each year. The causes of $80 \%$ of all maternal deaths are severe bleeding, infections, and high blood pressure during pregnancy and unsafe abortion. The report trends in maternal mortality show that the maternal mortality ratio for obese pregnant women was 4.6 times higher than underweight mothers. The maternal morbidity ratio reached $41 \%$ in underweight mothers and $70 \%$ in obese mothers. The obesity and underweight were still as a risk factor for maternal and neonatal mortality and morbidity. The annual number of maternal deaths dropped from more than 543,000 to 287,000 a decline of 47 per cent from 1990 to $2010{ }^{1}$ 
The Institute of Medicine in 1995 demonstrated that low maternal weight gain in the second trimester was associated with decreased birth weights ranging from 48 to 248 grams, dep 


\section{Method:}

After obtaining administrative permission from authorities of hospital, purpose of the study was explained to them and an informed consent was obtained before starting the study.

The present study was adopted an explorative approach and the Non experimental co-relational research design. $A$ total of 80 postnatal mothers who were diagnosed with pregnancy induced hypertension during their antenatal period were selected as samples by purposive sampling.

Eligibility criteria's were postnatal mothers with different levels of body mass index under the age group of 18-45 years and Postnatal mothers who have booked early that is before 12 weeks of gestation and having antenatal cand. Postnatal mothers with pre-existing medi were excluded. Body mass index table: It con mass index table of National academy of science the body mass index of selected samples. This incla categories of body mass index such as underm (<19.8) normal weight $(19.8-25)$, over weight $(25.1-$ and obese (> 29.1). The body mass index of mother assessed by Weight (KG)/ (Height in meter). 2 Part two also consist of recordings of body mass index

Tools developed by the researchers were validated and tested for its reliability. The equivalence of this tool was checked by inter observer method by using the formula number of agreements/ number of agreements + number of disagreements. The reliability obtained for maternal outcome checklist was $r 1=0.95$ and for neonatal outcome checklist was $r 1=0.93$ which indicating that the tools were reliable. Tools used were, Tool 1: demographic variable, Tool 2: It consist of body mass index table and recordings of body mass index values during first antenatal visit and weight at the time of admission for labour. Tool 3: pregnancy outcome checklist which includes maternal and foetal outcome.

The study was carried out using interview and analysis of records. Relevant information (background data) from the study group was collected for which the investigator personally interviewed each woman with the help yr dhe respopses were recorded in the space provided in the questionnaire and pregnancy outcome were marked in the checklist by analysing records.

\section{Results :}

Data Analysis Procedure: Statistical analysis was done using SPSS version 16. Frequency and percentage were computed for categorical variables like age groups, education, religion, occupation, income, parity, physical activity and diagnosis of samples with pregnancy-induced hypertension. Pearson correlation used to find out correlation between variables, Chi-Square test was used to find out an associate between BMI and selected 
condition increases) and type of delivery that is Incidence of LSCS was high among high BMI mothers. Results showed negative correlation between birth weight and diagnosis and gestational age and positive correlation between diagnosis and type of delivery.

Association between pregnancy outcome and selected demographic variables. Study findings revealed that following demographic variables are significantly associated with pregnancy outcome at 0.05 level.

There is a significant association between Occupation and $\mathrm{BMI} \chi^{2}=12.838 \mathrm{p}$ value $0.046<0.05$, Occupation and Birth weight $\chi^{2}=1.092 p$ value $.005<0.05$, physical activity and birth weight $\chi^{2}=10.47 p$ value $.033<0.05$, Diagnosis and type of delivery $\chi^{2}=17.16 p$ value $.000<0.05$, Diagnosis and birth weight $\chi^{2}=30.98 p$ value $.000<0.05$, Diagnosis and NICU care $\chi^{2}=14.61 p$ value $.001<0.05$

Table: 1 Demographic Variable

\begin{tabular}{|c|c|c|c|c|c|c|c|c|c|}
\hline & \multirow[t]{2}{*}{ Variables } & \multicolumn{2}{|c|}{ Under weight } & \multicolumn{2}{|c|}{ Normal weight } & \multicolumn{2}{|c|}{ Over weight } & \multicolumn{2}{|c|}{ Obese } \\
\hline & & $\mathbf{N}$ & $\%$ & $\mathbf{N}$ & $\%$ & $\mathbf{N}$ & $\%$ & $\mathbf{N}$ & $\%$ \\
\hline \multirow{5}{*}{ AGE } & $<20$ & 0 & 0 & 2 & 2.5 & 2 & 2.5 & 1 & 1.25 \\
\hline & $21-25$ & 2 & 2.5 & 27 & 33.75 & 12 & 15 & 5 & 6.25 \\
\hline & $26-30$ & 0 & 0 & 7 & 8.75 & 14 & 17.5 & 2 & 2.5 \\
\hline & $31-35$ & 0 & 0 & 2 & 2.5 & 2 & 2.5 & 1 & 1.25 \\
\hline & $36-40$ & 0 & 0 & 1 & 1.25 & 0 & 0 & 0 & 0 \\
\hline \multirow[t]{6}{*}{\begin{tabular}{|l} 
Education \\
\end{tabular}} & primary School & 0 & 0 & 1 & 1.25 & 2 & 2.5 & 0 & 0 \\
\hline & Middle school & 0 & 0 & 0 & 0 & 2 & 2.5 & 1 & 1.25 \\
\hline & Sec.education & 0 & 0 & 15 & 18.75 & 8 & 10 & 2 & 2.5 \\
\hline & PUC & 1 & 1.25 & 15 & 18.75 & 11 & 13.75 & 2 & 2.5 \\
\hline & Diploma & 0 & 0 & 2 & 2.5 & 1 & 1.25 & 0 & 0 \\
\hline & Graduate & 1 & 1.25 & 6 & 7.5 & 6 & 7.5 & 4 & 5 \\
\hline \multirow[t]{3}{*}{ Religion } & Hindu & 2 & 2.5 & 30 & 37.5 & 23 & 28.75 & 7 & 8.75 \\
\hline & Christian & 0 & 0 & 1 & 1.25 & 2 & 2.5 & 1 & 1.25 \\
\hline & Muslim & 0 & 0 & 8 & 10 & 5 & 6.25 & 1 & 1.25 \\
\hline \multirow[t]{5}{*}{ Income in Rs } & $<5000$ & 0 & 0 & 7 & 8.75 & 3 & 3.75 & 0 & 0 \\
\hline & $5001-10000$ & 0 & 0 & 15 & 18.75 & 9 & 11.25 & 5 & 6.25 \\
\hline & $10001-15000$ & 2 & 2.5 & 13 & 16.25 & 13 & 16.25 & 2 & 2.5 \\
\hline & $15001-20000$ & 0 & 0 & 1 & 1.25 & 3 & 3.75 & 0 & 0 \\
\hline & $>20001$ & 0 & 0 & 3 & 3.75 & 2 & 2.5 & 2 & 2.5 \\
\hline \multirow[t]{3}{*}{ Occupation } & Home maker & 1 & 1.25 & 36 & 45 & 27 & 33.75 & 8 & 10 \\
\hline & Skilled worker & 0 & 0 & 2 & 2.5 & 2 & 2.5 & 1 & 1.25 \\
\hline & Unskilled worker & 1 & 1.25 & 1 & 1.25 & 1 & 1.25 & 0 & 0 \\
\hline \multirow[t]{4}{*}{ Parity } & First pregnancy & 2 & 2.5 & 19 & 23.75 & 13 & 16.25 & 5 & 6.25 \\
\hline & Second pregnancy & 0 & 0 & 13 & 16.25 & 10 & 12.5 & 4 & 5 \\
\hline & Third pregnancy & 0 & 0 & 4 & 5 & 5 & 6.25 & 0 & 0 \\
\hline & Fourth pregnancy & 0 & 0 & 3 & 3.75 & 2 & 2.5 & 0 & 0 \\
\hline \multirow[t]{3}{*}{ Physical activity } & Sedentary worker & 2 & 2.5 & 24 & 30 & 14 & 17.5 & 5 & 6.25 \\
\hline & Moderate worker & 0 & 0 & 13 & 16.25 & 14 & 17.5 & 3 & 3.75 \\
\hline & Heavy worker & 0 & 0 & 2 & 2.5 & 2 & 2.5 & 1 & 1.25 \\
\hline \multirow[t]{3}{*}{ Diagnosis } & Gestational HT & 0 & 0 & 28 & 35 & 10 & 12.5 & 1 & 1.25 \\
\hline & Mild.PIH & 2 & 2.5 & 8 & 10 & 16 & 20 & 5 & 6.25 \\
\hline & Severe.PIH & 0 & 0 & 3 & 3.75 & 4 & 5 & 3 & 3.75 \\
\hline
\end{tabular}


Table : 2 Percentage distribution of Pregnancy Outcome

\begin{tabular}{|c|c|c|c|c|c|c|c|c|c|}
\hline & \multirow{2}{*}{$\begin{array}{l}\text { BMI } \\
\text { Outcome }\end{array}$} & \multicolumn{2}{|c|}{ Underweight } & \multicolumn{2}{|c|}{ Normal weight } & \multicolumn{2}{|c|}{ Overweight } & \multicolumn{2}{|c|}{ Obese } \\
\hline & & $\mathbf{N}$ & $\%$ & $\mathbf{N}$ & $\%$ & $\mathbf{N}$ & $\%$ & $\mathbf{N}$ & $\%$ \\
\hline \multirow[t]{2}{*}{ Delivery } & NVD & 1 & 1.25 & 25 & 31.25 & 15 & 18.75 & 2 & 2.5 \\
\hline & LSCS & 1 & 1.25 & 14 & 17.5 & 15 & 18.75 & 7 & 8.75 \\
\hline \multirow[t]{3}{*}{ Birth weight } & Normal & 0 & 0 & 24 & 30 & 14 & 17.5 & 4 & 5 \\
\hline & LBW & 2 & 2.5 & 12 & 15 & 15 & 18.75 & 5 & 6.25 \\
\hline & VLBW & 0 & 0 & 3 & 3.75 & 1 & 1.25 & 0 & 0 \\
\hline \multirow[t]{2}{*}{ Gestational age } & Full term & 1 & 1.25 & 29 & 36.25 & 23 & 28.75 & 5 & 6.25 \\
\hline & Preterm & 1 & 1.25 & 10 & 12.5 & 7 & 8.75 & 4 & 5 \\
\hline \multirow[t]{2}{*}{ NICU care } & No & 0 & 0 & 31 & 38.75 & 20 & 25 & 5 & 6.25 \\
\hline & Yes & 2 & 2.5 & 8 & 10 & 10 & 12.5 & 4 & 5 \\
\hline
\end{tabular}

Table: 3 BMI and correlation

\begin{tabular}{|l|c|c|c|c|c|c|}
\hline & \multicolumn{2}{|c|}{ BMI } & \multicolumn{2}{c|}{ Birth weight } & \multicolumn{2}{c|}{ Diagnosis } \\
\hline & $\mathrm{r}$ value & $\mathrm{P}$ value & $\mathrm{r}$ value & $\mathrm{P}$ value & $\mathrm{r}$ value & $\mathrm{P}$ value \\
\hline Diagnosis & $.293^{* *}$ & .008 & $-.499^{* *}$ & .000 & - & - \\
\hline Type of delivery & $.261^{*}$ & .019 & - & - & $.449^{* *}$ & .000 \\
\hline Gestational age & - & - & $-.494^{* *}$ & .000 & & \\
\hline
\end{tabular}

**. Correlation is significant at the 0.01 level (2-tailed).

*. Correlation is significant at the 0.05 level (2-tailed).

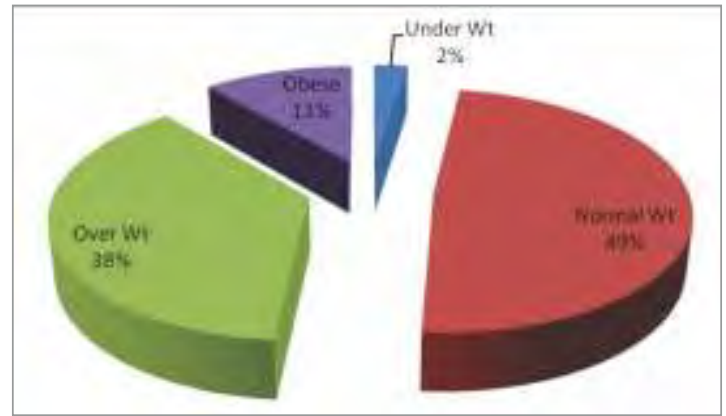

Figure 1 Distribution of postnatal mothers according to their BM I.

\section{Discussion :}

The present study indicated that maternal pre pregnancy weight related with greater risks of pregnancy-induced hypertension, caesarean delivery, preterm delivery and prematurity, birth weight at birth. Also reveals that there is a correlation between BMI and pregnancy outcome and association between demographic variable and pregnancy outcome.

A comparative study conducted to investigate the impact of maternal obesity on pregnancy outcomes. Rates of pregnancy complications and neonatal outcomes were collected from perinatal data list and compared between women with normal pre pregnancy body mass index and those with an obese pre pregnancy body mass index. Rates of pregnancy complications and neonatal outcomes were also evaluated by the level of obesity, severe obesity, and morbid obesity (BMI>30, BMI=35-39.9 and, BMI $>40$ ). Rates of gestational diabetes and gestational hypertension were higher for obese $62 \%$ versus normal weight only $10 \%$ in gravid. Women with morbid or severe obesity had a greater incidence of gestational diabetes and gestational hypertension. This is similar to present study. ${ }^{9}$

Another study which was similar to present study prospective population-based cohort study was done to evaluate morbidly obese (BMI>40) women have an increased risk of pregnancy complications and adverse perinatal outcomes. The result of the study was an increased risk of the following outcomes: preeclampsia 20 $\%$, ante partum stillbirth $15 \%$, caesarean delivery $35 \%$, instrumental delivery $12 \%$, shoulder dystocia $10 \%$, meconium aspiration $40 \%$, foetal distress $30 \%$, early neonatal death $7 \%$, and large-for-gestational age $10 \%$ was found women with BMIs between 35.1 and 40 but to a lesser degree compared to BM Is above 40.33 In this study $8.75 \%$ of obese mother were delivered by LSCS and $6.25 \%$ of newborn babies were LBW. ${ }^{10}$

\section{Conclusion:}

Obesity and under weight is a leading, preventable cause of mortality worldwide and authorities view it as one of the 
most serious public health problems of the 21 st century. In developing countries the obesity and underweight were still as a risk factor for maternal and neonatal mortality and morbidity. Preeclampsia increases maternal and perinatal morbidity and mortality rates. This study revealed that there is a correlation between BMI and pregnancy outcome. Result of this present study and other studies cited in this article are stating that there is association

\section{References:}

1. Hendler I, Goldenberg RL, M ercer BM, Iams JD, M eis PJ, M oawad AH, MacPherson CA, Caritis SN, M iodovnik M, Menard KM, Thurnau GR, Sorokin $Y$ Association between maternal body mass index and spontaneous and indicated preterm birth. American journal of obstetrics and gynaecology.2005Jan; 19(2):P. 882-6.

2. Bell A W, Ehrhardt R A. Regulation of placental nutrient transport and implications for foetal growth. Journal of Nutrition.2002Feb; 15(1):P. 215-35.

3. Nan Li, Enqing Liu, Jia Guo, Lei Pan, Baojuan Li, Ping Wang, Jin Liu, Yue Wang, Gongshu Liu, Andrea A. Baccarelli, Lifang Hou, Gang Hu (2013) Maternal Prepregnancy Body M ass Index and Gestational Weight Gain on Pregnancy Outcomes. PLOSONE; 8:12, 2-7

4. Perinatol J, Joy S, Istwan N, Rhea D, Desch C, Stanziano G. Assess the effect of underweight on maternal and neonatal outcome. Wake Forest University, Winston-Salem, North Carolina 2008M ay; 26(5):P. 345-9.

5. M rozikiewiczA, Drews K, Nowocien G, Kaluba-Skotarczak A. Obesity in pregnant women as a problem in obstetrics. Journal of Geburtshilfe between BM I and Pregnancy outcome which is modifiable.

All women who are in reproductive age group and under risk to develop pregnancy induced hypertension need to be educated about to maintenance of normal weight before pregnancy. Nurses have more responsibility on creating awareness among women how to maintain normal weight to avoid development of complications to the mother and newborn.

neonatal complication.2007 M ar; 78(3):P.234-8.

6. Nilsen R M, Lise A, Monsen B, Midttun O, Nygard O, Pedersen E R. $M$ aternal tryptophan and kynurenine pathway metabolites and risk of preeclampsia. American journal of Obstetrics and gynecology. 2009 Aug; 119(6):P.1243-50.

7. Raatikainen $\mathrm{K}$, Heiskanen $\mathrm{N}$, Heinonen S. Transition from overweight to obesity worsens pregnancy outcome in a body mass index dependent manner. Department of Obstetrics and Gynecology, Kuopio University Hospital, Kuopio, Finland. 2006 Jan; 14(1):P.165-71.

8. Watkins $M L$, Rasmussen $S A$, Honein M A, Botto L D, Moore C A. Division of Birth Defects and Developmental Disabilities. American journal of paediatrics. 2003 M ay; 111(5):P.1152-8.

9. Alanis M C, Goodnight W H, Hill EG, Robinson CJ, Villers M S. Impact of maternal obesity on pregnancy outcomes. Acta Obstetrical and Gynecological Scand. Charleston, South Carolina. 2010 Jul; 89(7):P.924-30.

10. Blomberg M . M aternal Obesity and Risk of Postpartum Hemorrhage. Obstetrics and Gynecology .2011M ar; 11(8):P. 561-8. 